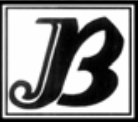

J. bio-sci. 14: 17-23, 2006

ISSN 1023-8654

\title{
A REVISION OF INDIAN SPECIES OF PARURIOS GIRAULT WITH A NEW RECORD OF PAPUOPSIA BOUČEK (HYMENOPTERA: PTEROMALIDAE) FROM INDIA
}

\author{
T C Narendran ${ }^{1 *}$, Sabu K Thomas ${ }^{2}$ and P A Sinu ${ }^{3}$ \\ ${ }^{1}$ Department of Zoology, University of Calicut, Kerala - 673 635, India \\ 2Department of Zoology, St. Joseph's College, Devagiri, Calicut, Kerala - 673 008, India \\ ${ }^{3}$ Ashoka Trust for Research in Ecology and Environment, Bangalore, Karnataka - 560 024, India
}

\begin{abstract}
Two new species of Parurios Girault viz. P. bouceki Narendran sp. nov. and $P$. sringericus Narendran sp. nov. are described from India. The female of $P$. keralensis Narendran is also described. A key to Indian species of Parurios is provided. The genus Papuopsia is recorded for the first time from India.
\end{abstract}

Keywords: Pteromalidae, Chalcidoidea, Parurios, new species, key, Papuopsia, new record, India.

Abbreviations: DZUC = Department of Zoology, University of Calicut, Kerala, India; F1-F7 = Funicular segments 1-7; $\mathrm{POL}=$ Postocellar distance; OOL = Ocellocular distance; MV = Marginal vein; PMV = Post marginal vein; SMV = Submarginal vein; STV = Stigmal vein; T1 = First gastral tergite; UCDC = Bohart Museum, University of California, Davis, USA; ZSIC = Zoological Survey of India, Calcutta (= Kolkatta), India; ZSIK = Western Ghats Regional Station, Zoological Survey of India, Kozhikode, Kerala, India.

\section{Introduction}

The genus Parurios was raised by Girault (1913) from Australia. According to Bouček (1988) the genus is represented in South Asia, New Guinea and Solomon Islands besides Australia. From India so far only one species is reported (Narendran et al. 2000). Bouček (1988) stated without mentioning the species name that one species (probably undescribed) is known to occur in India. In this paper two new species of Parurios are described. The female of $P$. keralensis is described for the first time since the original description of $P$. keralensis actually refers to a male and not to a female as mentioned there in. Sureshan (2005) reported the genus Papuopsia Bouček from Sri Lanka based on the species $P$. striata Sureshan. In this paper, we record the same genus and species from India for the first time. The new species described are deposited in Zoological Survey of India, Kolkatta (ZSIC).

\section{Materials and Methods}

The specimens were collected by using sweep net and pit-fall traps. They are curated by methods described by Narendran (2001).

\section{KEY TO SPECIES OF PARURIOS GIRAULT OF INDIA}

1. Scrobe relatively long (Fig. 3) separated from front ocellus by a distance as long as diameter of front ocellus, exceeding well over middle length of eye from toruli; clava as long as combined length of F7 + F6 + F5; petiole smooth and shiny without longitudinal carinae, its maximum posterior width $1.13 \mathrm{x}$ its dorsal length sringericus Narendran sp. nov.

\footnotetext{
* To whom all correspondence should be addressed
} 
-- Scrobe relatively shorter than above (Figs.2 \&7), at the most reaching mid level of eye from toruli; clava distinctly shorter than combined length of F7 + F6 + F5; petiole with longitudinal carinae; its maximum width variable

2. Axillae and pronotum pink; head mostly brownish pink with vertex and occiput darker; forewing with 3 infumate patches (Fig.1); petiole a little longer than half length of hind coxa bouceki Narendran sp. nov.

-- Axillae, pronotum and head black; forewing not as above, hyaline; petiole one-third as long as hind coxa keralensis Narendran

\section{Genus Parurios Girault}

Parurios Girault 1913: 84-85. Type species Parurios australiana Girault by monotypy.

Uriolelaps Girault 1915: 201. Type species Uriolelaps argenticoxae Girault (Bouček 1988 synonymized).

Emersonia Girault 1933: 441. Type species Emersonia atriscutum Girault (Bouček 1988 synonymized).

Diagnosis: Similar to Dipara Walker but dorsal bristles on vertex and mesosoma much stronger than those of Dipara. Notauli arched and approaching each other on the posterior part of mesoscutum. Male is plumber than that of Dipara.

Biology: Bouček (1988) reported one Indian species (not named) from the curculionid Athesapeuta cyperi Marshall, feeding on roots of Cyperus rotundus.

Distribution: South Asia, New Guinea, Solomon Islands and Australia (Bouček 1988), Narendran et al. (2000).

Parurios bouceki Narendran sp. nov. (Figs. $1 \& 2$ )

Holotype: Female: Length $2.73 \mathrm{~mm}$. Head pale brownish pink with vertex and occiput a little darker; antenna blackish brown except clava, pedicel and scape which are pale brownish yellow; eyes pale yellowish grey; ocelli blackish brown; pronotum pink; mesoscutum black except a small pinkish strip on anterior margin; scutellum black except a pinkish median narrow longitudinal strip and pinkish area on left side of sublateral groove; axillae pink; propodeum black with median part slightly pink; prepectus pinkish black; tegula pale brown; all coxae pinkish brown; trochanter pale brown; fore femur brown with apex paler; mid and hind femur brown with apex paler; mid and hind femora pale yellow with one-third of apical parts pinkish brown; all tibiae and tarsi pale yellow. Metasoma black except pale brown ventral margin. Wings hyaline with 3 infumate patches (Fig.1).

Head: Width in front view subequal to its length; width in dorsal view 4.2x its median length; frons distinctly reticulate; scrobe short, hardly reaching middle level of eye, shorter than scape, cross striate-reticulate, margins ecarinate; inter antennal carina present; clypeus delimited; anterior tentorial pits distinct; mandibles tridentate, innermost teeth weak; maximum diameter of eye in profile $3.2 \mathrm{x}$ as long as malar space; malar sulcus distinct and complete; temples narrow or almost indistinct in side view; POL 1.83x OOL; vertex with 3 pairs of stout setae directed forwards. Antenna inserted at level of ventral margin of eyes; anellus indistinct; scape not reaching front ocellus. Relative length: width of antennal segments: scape $=41: 8$; pedicel $=14: 7$; $F 1=10: 7 ; F 2=11: 7 ; F 3=10: 8 ; F 4=12: 8 ; F 5=10: 9 ; F 6=7.5: 10 ; F 7=8: 10 ;$ clava $=23: 10$. 


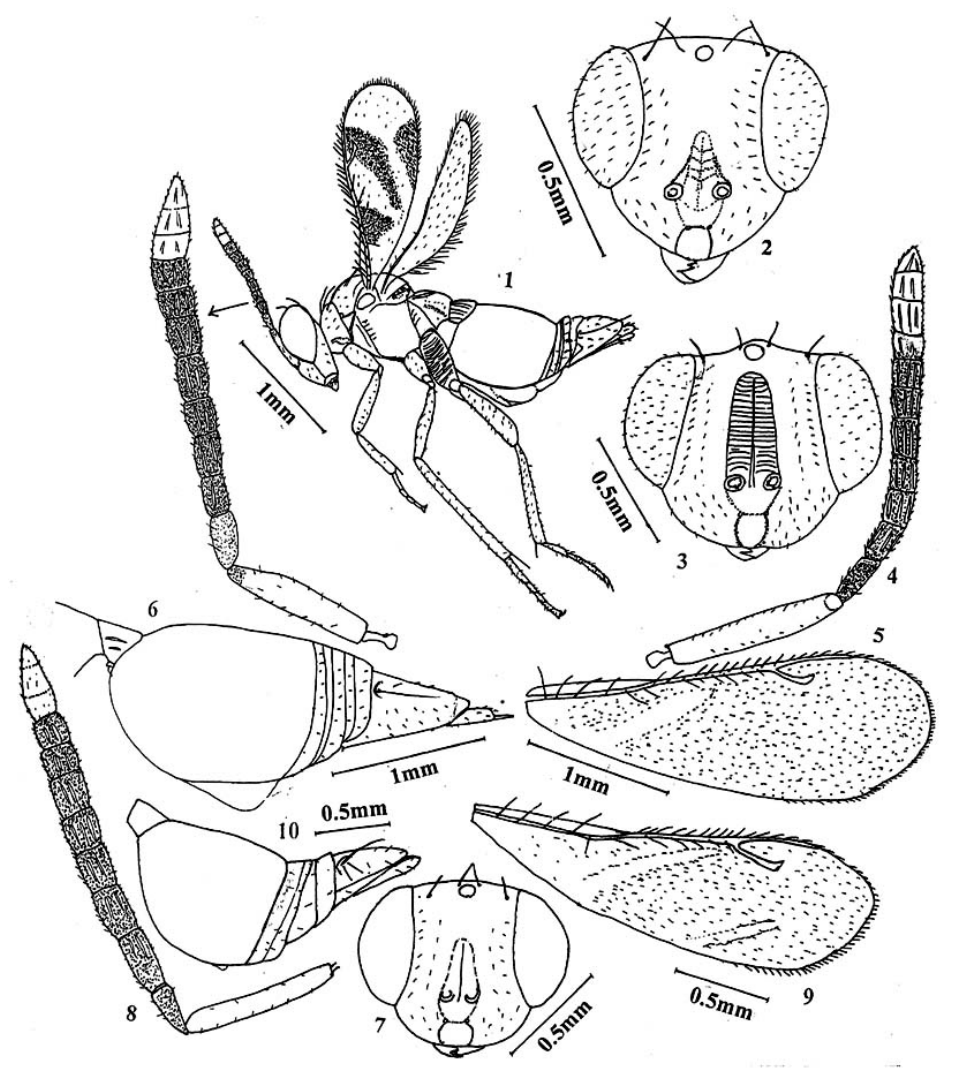

Figs. 1-2 Parurios bouceki Narendran sp. nov. Female (1) Body profile (2) Head in front view

Figs. 3-6 Parurios sringericus Narendran sp. nov. Female (3) Head in front view (4) Antenna (5) Forewing (6) Metasoma Figs. 7-10 Parurios keralensis Narendran Female (7) Head in front view (8) Antenna (9) Forewing (10) Metasoma

Mesosoma: Pronotum reticulate, with a row of 6 stout setae near posterior margin and with several shorter pubescence all over dorsal side; pronotum shorter than mesoscutum (6: 10); mesoscutum reticulate on anterior half and cross striate on posterior half with a pair of stout setae placed about $2 x$ as far from transcutal suture as the anterior scutellar setae; notauli arched and approaching each other on posterior part of mesoscutum; each scapula with a stout seta near posterior distal margin; scutellum including frenal area, a little shorter than mesoscutum (9: 10), with a pair of stout setae near transcutellar suture and another stouter pair on distal side of basal margin of frenum; area anterior to frenum reticulate; frenum with a strong median longitudinal carina and several weak carinae on sides; frenal area a little shorter than remaining anterior part of scutellum (4: 5); prepectus rugulose; hind coxa strongly cross-carinate dorsally. Propodeum with an anterior median areola followed by a median longitudinal carina, costula present; propodeal spiracle separated from posterior margin of metanotum by $2 x$ diameter of spiracle. Forewing $2.8 \mathrm{x}$ as long as wide; SMV with 5 dorsal setae; relative lengths of veins $S M V=15 ; M V=21 ; P M V=13 ; S T V=6$. 
Metasoma: Longer than mesosoma (50: 37), petiole about one-third as long as T1 in dorsal view, with several longitudinal carinae, $1.33 x$ as long as its width in dorsal view, distinctly shorter than hind coxa (7: 15); T1 largest; one of the cercal setae longer than others; hypopygium reaching beyond half length from base of gaster.

Male: Unknown.

Host: Unknown.

Material examined: Holotype: Female, INDIA, Kerala, Wayanad, Thirunelli $\left(11^{\circ} 41^{\prime} \mathrm{N} 76^{\circ} 16^{\prime} \mathrm{E}\right), 11 . x i .2004$, coll. K T Sabu (ZSIC)

Etymology: Named in honour of $\operatorname{Dr} Z$ Bouček (London) for his significant contributions on Chalcidology.

Parurios sringericus Narendran sp. nov. (Figs. 3-6)

Holotype: Female: Length 4.5mm. Black with following parts as follows: eye and ocelli pale reflecting yellow; antenna brown with scape, distal half of $\mathrm{F} 7$ and clava whitish yellow; mandibles black; cervix pinkish brown; fore and mid coxae lever brown with apices paler; hind coxa black with apex pale yellowish brown; all trochanters pale brownish yellow; fore femur dark brown with basal part paler; mid femur yellow on proximal area (5/10), remaining area except apex reddish brown, apex pale yellow; hind femur yellow (8/13), remaining part reddish brown except pale yellow apex; fore tibia pale yellow with median part slightly brown; mid tibia yellow (1/3) basally and remaining part brown; hind tibia pale yellow; all tarsi pale yellow; tegula pale reddish brown.

Head: Width in front view 1.19x its length, width in dorsal view $6 \mathrm{x}$ as its median length; frons reticulate on part near vertex, preorbital area and on face; scrobe and adjoining areas cross carinate; scrobe reaching near front ocellus, as long as scape; clypeus delimited, tentorial pits distinct; mandibles tridentate with inner most teeth weak; maximum diameter of eye in profile $2 \mathrm{x}$ its width, $3.6 \mathrm{x}$ as long as malar space; malar sulcus distinct and complete; temples narrow; POL 1.25x OOL; vertex with 3 pairs of stout setae, directed forwards. Antenna inserted at level of ventral margin of eyes; anellus indistinct; scape not reaching front ocellus. Relative length: width of antennal segments: scape $=48: 8$; pedicel $=15: 5 ; F 1=11: 5 ; F 2=10: 7 ; F 3=9: 7$; $F 4=10: 7 ; F 5=8: 8 ; F 6=8: 8 ; F 7=8: 8 ;$ clava $=24: 9$.

Mesosoma: Pronotum reticulate with a row of 4 stout setae near posterior border and with several short pubescence all over dorsal side; pronotum shorter than mesoscutum (7:11); mesoscutum with dense minute pubescence and a pair of stouter setae placed about $2 x$ as far from transcutal suture as the anterior scutellar setae; notauli arched and approaching each other on posterior part of mesoscutum; mesoscutum reticulate on most parts with a weak cross reticulation on region near transcutal suture; each scapula with a stout seta near posterior distal margin; scutellum including frenum distinctly shorter than mesoscutum (11: 15) with a pair of stout setae near transcutellar suture and another stouter pair on distal basal margin of frenum; area anterior to frenum reticulate; frenum with 11 strong longitudinal carinae; frenal area shorter than scutellar area anterior to it (4: 7); prepectus striate-reticulate; hind coxa with strong cross carinae on dorsal side. 
Propodeum with an anterior median areola followed by a median longitudinal carina; costula strong; propodeal spiracle separated from metanotum by diameter of spiracle. Forewing $2.75 x$ as long as wide. SMV with 4 dorsal setae; relative lengths of veins: $S M V=35 ; M V=34 ; P M V=21 ; S T V=11$; forewing with linea clava distinct.

Metasoma: Longer than mesosoma (36: 22); petiole a little shorter than one-third dorsal length of T1 (13: 46), without any longitudinal carinae on dorsal side, mostly smooth and shiny, its posterior most width a little more than its dorsal length (9: 8), shorter than half length of hind coxa (11: 27); T1 longest; one of the cercal setae longer than others; hypopygium hardly reaching middle length of gaster (50: 104).

Male: Unknown.

Host: Unknown.

Material examined: Holotype: Female, INDIA, Karnataka, Sringeri (1302 $\left.25^{\prime} N 75^{\circ} 15^{\prime} E\right)$, 10.iv.2001, coll. P A Sinu (ZSIC).

Etymology: Named after the type locality Sringeri.

Parurios keralensis Narendran (Figs. 7-10)

Parurios keralensis Narendran, in Narendran et al. 2000 : 137-139, India (ZSIK).

Since the available original description is based on male (erroneously described as 'female'), the female is described hereunder for the first time.

Female: Length $3.2 \mathrm{~mm}$. Black with following parts as follows: eye pale reflecting yellow with black tinge; ocelli dark brown; antenna dark brown with clava pale brownish yellow and scape brown. Fore and mid coxae brownish black; hind coxa basal half black, distal half pale brownish yellow; all trochanters pale brownish yellow; fore femur completely darkish brown; mid femur pale yellow on basal half; distal half dark brown with apex paler; hind femur similar in colour to mid femur; all tibiae and tarsi pale yellow; all pretarsi dark brown. Wings hyaline with brownish tinge.

Head: Width in anterior view $1.2 x$ its length, width in dorsal view $3.75 x$ its median length; frons reticulate; scrobe reaching at mid level of eye; scrobe cross carinate; interantennal carina weak; clypeus delimited; anterior tentorial pits distinct; mandibles tridentate with inner most teeth blunt and weak; maximum length of eye in profile $2 \mathrm{x}$ its width, $3.5 \mathrm{x}$ as long as malar space; malar sulcus weak but complete, temples thin, almost absent in side view; POL 1.5x OOL; vertex with 3 pairs of setae directed forwards. Antenna inserted slightly above level of ventral margin of eyes; anellus indistinct; scape not reaching front ocellus. Relative length: width of antennal segments: Scape $=43: 6$; pedicel $=14: 6 ; F 1=17: 6 ; F 2=15: 8 ; F 3=11: 8 ; F 4=10: 10$; $F 5=11: 10 ; F 6=8: 10 ; F 7=8: 9 ;$ clava $=20: 8$.

Mesosoma: Pronotum reticulate, with a row of 3 pairs of stout setae near posterior border and with several short pubescence all over dorsal side; pronotum shorter than mesoscutum (8: 11). Mesoscutum with dense minute pubescence and a pair of stouter setae placed 1.6x as far from transcutal suture as the anterior 
scutellar setae; notauli arched and approaching each other on posterior part of mesoscutum; mesoscutum reticulate almost completely with hardly any cross reticulation near transcutal suture; each scapula with a stout seta near posterior distal margin; scutellum including frenum distinctly shorter than mesoscutum (9: 12) with a pair of stout setae near transcutal suture and another pair on the basal margin of frenum; area anterior to frenum reticulate; frenal area with strong 11 longitudinal carinae; frenal area shorter than scutellar area anterior to it; prepectus weakly reticulate; hind coxa with moderately strong cross carinae on dorsal side. Propodeum with an anterior median areola followed by a median longitudinal carina; costula weak; propodeal spiracle separated from metanotum by a distance equal to $2.5 \mathrm{x}$ diameter of spiracle. Forewing $3.2 \mathrm{x}$ as long as wide; SMV with 4 dorsal setae; relative lengths of veins: $S M V=41 ; M V=31 ; P M V=22 ; S T V=13$; forewing with linea clava distinct.

Metasoma: Longer than mesosoma (19: 11), petiole a little shorter than one-third length of T1 in dorsal view (7: 23), with weak longitudinal lines on dorsal side, its posterior width a little shorter than its dorsal length (5: 6 ); one-third as long as hind coxa; T1 largest; one of the cercal setae on each side longer than others; hypopygium not reaching middle of gaster (32: 77).

Male: See original description by Narendran et al. (2000) under 'Female'.

Host: Unknown.

Material examined: Female, INDIA, Kerala, Thrissur, Vazhachal (10 $18^{\prime} \mathrm{N} 76^{\circ} 24^{\prime}$ E), 2.iii.2005, coll. T. C. Narendran \& party (ZSIC).

Papuopsia striata Sureshan

Papuopsia striata Sureshan 2005. Holotype Female, Sri Lanka (UCDC)

Sureshan (2005) recorded this species from Sri Lanka. In this present paper we record this species from India for the first time.

\section{Material examined}

1 Female, INDIA, Kerala, Malappuram, Calicut University campus ( $\left.11^{\circ} 7^{\prime} \mathrm{N} 75^{\circ} 5^{\prime} \mathrm{E}\right), 2 . x i .1980$, coll. T. C. Narendran \& party (DZUC).

\section{Acknowledgements}

The first author is grateful to the University of Calicut for facilities to do this research.

\section{References}

Bouček Z (1988) Australasian Chalcidoidea (Hymenoptera). A biosystematic revision of genera of fourteen families, with a reclassification of species. CAB International, Wallingford, Oxon, U.K. 832 pp.

Girault A A (1913) New genera and species of Chalcidoid Hymenoptera in South Australian Museum. Trans. R. Soc. Aust. 37: 67-115. 
Girault A A (1915) Australian Hymenoptera Chalcidoidea - VIII. The family Miscogasteridae with descriptions of new genera and species. Mem. Qd. Mus. 4: 185-202.

Girault A A (1933) 'Some beauties inhabitant not of the boudoirs of commerce but of natures bosom-new insects' 2pp (Girault: Brisbane). 304-305. Privately published papers of Girault compiled by G Gordh, A S Menke, E C Dahms \& J C Hall 1979. Mem. Amer. Ent. Inst. 28: 1-400.

Narendran T C, Mini T V and Karmaly K A (2000) A new species of Parurios Girault (Hymenoptera: Pteromalidae: Diparinae) from Kerala (India). Bull. Pure and Appl. Sci. 19 A (2): 137-140.

Narendran T C (2001) Parasitic Hymenoptera and biological control: vi+190pp Palani Paramount Publications, Palani, India (ISBN 81-85517-62-2).

Sureshan P M (2005) First record of Papuopsia Bouček from the Oriental region with the description of a new species from Sri Lanka (Hymenoptera: Chalcidoidea: Pteromalidae). Rec. zool. Surv. India: 105 (Part 3-4): 81-84. 